\title{
Cerebral oximetry for cesarean delivery in a Moyamoya case
}

\author{
Muhammad Ajmal $\cdot$ Patrick Thornton
}

Received: 10 December 2013/ Accepted: 10 January 2014/Published online: 29 January 2014

(C) Japanese Society of Anesthesiologists 2014

Keywords Cerebral oximetry $\cdot$ Moyamoya disease . Cesarean delivery $\cdot$ Oxytocin

To the Editor:

Patients with Moyamoya disease have abnormal intracranial blood vessels [Online Resource 1], the presence of which results in frequent strokes. Anesthesia further enhances the risk. We report cerebral oxygen saturation $\left(r \mathrm{SO}_{2}\right)$ observations using noninvasive near-infrared spectroscopic (NIRS) cerebral oximetry during a cesarean delivery (CD) under combined spinal epidural anesthesia in a Moyamoya case.

A 30-year-old $\mathrm{G}_{1} \mathrm{P}_{0}$ Moyamoya patient had an elective $\mathrm{CD}$ at 37 weeks. Her $r \mathrm{SO}_{2}$ was monitored using an NIRS cerebral oximeter. Eight milligrams of intrathecal heavy bupivacaine was sufficient for an optimum block. An intravenous bolus of $5 \mathrm{IU}$ oxytocin at a volume of $5 \mathrm{ml}$ was injected over a span of 1 min immediately following the delivery. Her $r \mathrm{SO}_{2}$ remained normal (60-75\%) and was relatively higher after the delivery [Online Resource 2]. We postulate that the increase in $r \mathrm{SO}_{2}$ after the delivery resulted from oxytocin-induced cerebral vasodilatation.

Electronic supplementary material The online version of this article (doi:10.1007/s00540-014-1790-1) contains supplementary material, which is available to authorized users.

M. Ajmal $(\square)$

Department of Anesthesia, Coombe Women and Infants

University Hospital, Dublin, Ireland

e-mail: ajmal_c@hotmail.com

P. Thornton

Department of Anesthesia, Rotunda Hospital, Dublin, Ireland
Oxytocin leads to dilatation or constriction in a myriad of blood vessels [1]. It has a vasopressin-like weak vasoconstrictive effect, and some reports [2] suggest that it may reduce cerebral blood flow (CBF), although other articles suggest an increase in $\mathrm{CBF}$ in experimental animals [3]. The $r \mathrm{SO}_{2}$ monitoring in obstetric anesthesia is currently scarce. We propose that $r \mathrm{SO}_{2}$ should be monitored in Moyamoya patients undergoing anesthesia, particularly when oxytocin is administered.

Acknowledgments We extend our thanks to Dr. R. Mhuircheartaigh from the Department of Anaesthesia, Mater Hospital, Dublin, Ireland, for facilitating our use of the cerebral oximeter.

\section{Conflict of interest None.}

Consent This report is presented with the written consent of the patient.

\section{References}

1. Ajmal M. Oxytocin at caesarean section: are we giving too much? BJOG. 2010;117:118-9.

2. Stolz-Born G, Widder B, Born J. Vascular effects of oxytocin on human middle cerebral artery determined by transcranial Doppler sonography. Regul Pept. 1996;62:37-9.

3. Suzuki Y, Satoh S, Kimura M, Oyama H, Asano T, Shibuya M, Sugita K. Effects of vasopressin and oxytocin on canine cerebral circulation in vivo. J Neurosurg. 1992;77:424-31. 